\title{
Suppression of oxidation of high chromium steels at elevated temperatures in steam atmosphere by alumina-based coating film grown by chemical solution deposition process
}

\author{
Akio SAYANO, Toshiyuki TAZAWA, ${ }^{, \dagger}$ Liang YAN, ${ }^{*}$ Masashi TAKAHASHI, \\ Kenichi OKUNO* and Itaru MURAKAMI** \\ Power and Industrial Systems R\&D Center, Toshiba Corp., 8 Shinsugita-cho, Isogo-ku, Yokohama 235-8523, Japan \\ *Power and Industrial Systems R\&D Center, Toshiba Corp., 2-4 Suehiro-cho, Tsurumi-ku, Yokohama 230-0045, Japan \\ **Thermal \& Hydro Power Systems \& Services Division, Toshiba Corp., 2-4 Suehiro-cho, Tsurumi-ku, Yokohama 230-0045, Japan
}

The surface roughness in moving and stationary blades of steam turbines is known to become rougher through steam oxidation during plant operation, resulting in the degradation of the turbine performance. The formation of an $\mathrm{Al}_{2} \mathrm{O}_{3}-\mathrm{SiO}_{2}$ based coating film on high chromium steel, which is used in moving and stationary blades, through chemical solution deposition (CSD) is attempted to suppress the increase of surface roughness. The arithmetic average roughness $R_{\mathrm{a}}$ and maximum height $R_{\mathrm{z}}$ after an oxidation test in a steam atmosphere at $873 \mathrm{~K}$ for $1,000 \mathrm{~h}$ were equal to 3.0 and $19.4 \mu \mathrm{m}$, respectively, for high chromium steels without coating, while those for high chromium steel with an $\mathrm{Al}_{2} \mathrm{O}_{3}-\mathrm{SiO}_{2}$ based coating were 0.10 and $1.0 \mu \mathrm{m}$, respectively. Therefore, the formation of a coating film is proven to significantly suppress the roughening of the surface. The observation of the cross-section texture near the high chromium steel substrate surface of both specimens showed that a two-layer oxide film forms on the surface of the non-coated specimen; the outer layer consists of $\mathrm{Fe}_{3} \mathrm{O}_{4}$, whereas the inner layer comprises $(\mathrm{Fe}, \mathrm{Cr})_{3} \mathrm{O}_{4}$ and $\mathrm{CrO}_{2}$. This film forms a very coarse texture. On the other hand, the oxide film does not form on high chromium steel with an $\mathrm{Al}_{2} \mathrm{O}_{3}-\mathrm{SiO}_{2}$ based coating film deposited using $\mathrm{CSD}$; the $\mathrm{Al}_{2} \mathrm{O}_{3}-\mathrm{SiO}_{2}$ based coating film remains as the topmost surface after testing. A thin intermediate layer with a thickness smaller than $0.1 \mu \mathrm{m}$ forms between the high chromium steel substrate and the coating film. Its thickness increases with increasing the temperature and reaches approximately $0.5 \mu \mathrm{m}$ with heat treatment at $973 \mathrm{~K}$ for $1,000 \mathrm{~h}$. This layer consists of $\mathrm{Cr}, \mathrm{Mn}, \mathrm{Al}, \mathrm{Si}$, and $\mathrm{O}$.

(2016 The Ceramic Society of Japan. All rights reserved.

Key-words : Steam turbine, Surface roughness, Oxidation, High chromium steel, Chemical solution deposition, Aluminum oxide

[Received August 27, 2015; Accepted January 31, 2016]

\section{Introduction}

Owing to its strength and creep properties, high chromium steel is currently used in moving and stationary blades of steam turbines. As these blades are exposed to a steam flow, the surface roughness is suppressed beforehand considering the aerodynamic characteristics. However, the surface roughness of the blades gradually increases by steam oxidation during plant operations. This causes turbulence in the steam flow, degradation of the aerodynamic characteristics, and a decrease of the turbine efficiency. Figure 1 shows a schematic of the turbulence generated in a steam flow when the surface roughness increases. Improving the oxidation resistance of the moving and stationary blades can retain the initial surface roughness, and therefore maintain the turbine performance, for a longer time.

Using Ni-based or Co-based superalloys in moving and stationary blades can improve the antioxidation properties; ${ }^{1)}$ however, this is not realistic because of the high cost of these metals.

Thermal spraying and coating such as through physical vapor deposition (PVD) or chemical vapor deposition (CVD) are examples of effective methods to increase the oxidation resistance.

\footnotetext{
Corresponding author: T. Tazawa; E-mail: toshiyuki.tazawa@ toshiba.co.jp

* Preface for this article: Dol http://dx.doi.org/10.2109/jcersj2.124.P1-1
}

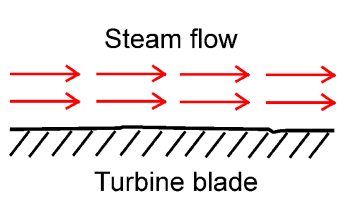

(a) Surface roughness; smooth

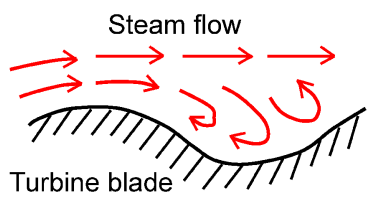

(b) Surface roughness; rough

Fig. 1. Conceptual scheme expresses the influence of surface roughness on steam flow.

However, the surface roughness increases during thermal spraying processing, whereas PVD and CVD require special apparatuses and are not suitable for large components, as the part to be coated must be kept in a vacuum chamber during processing. ${ }^{2)-4)}$

Chemical solution deposition (CSD) is a method to form a thin ceramic film on the surface of a metal substrate by depositing a ceramic precursor solution on the metal substrate surface, and then decomposing the ceramic precursor by heat treatment. This method can be applied to large parts with complex shapes, as the process is simple, low cost, and does not need a special apparatus. ${ }^{5-9)}$

There are relatively many studies on the improvement of the oxidation resistance of metals through CSD. Sanctis et al. formed a $\mathrm{SiO}_{2}$ film on the surface of stainless steel and found that the oxidation resistance improved at 923 and $1123 \mathrm{~K}$ in air. ${ }^{10)}$ Atik et al. formed $\mathrm{ZrO}_{2}$ film on the surface of ferrite steel using CSD and confirmed that the coating suppresses the oxidation through 
assessment of the oxidation resistance at $1073 \mathrm{~K}$ in air. ${ }^{11)}$ Furthermore, Guglielmi et al. formed a $\mathrm{SiO}_{2}-\mathrm{B}_{2} \mathrm{O}_{3}$ based coating film on the surface of carbon steel by CSD, investigated the oxidation resistance at $823 \mathrm{~K}$ in air, and reported that the weight gain by oxidation can be suppressed by coating. ${ }^{12)}$

As mentioned above, several studies have been conducted on the enhancement of the oxidation resistance by coating of ceramics through CSD. However, most investigations focus on the oxidation resistance in air, and only a few studies on the oxidation resistance in a steam atmosphere. Moreover, there is barely any research focusing on the suppression of surface roughness through coating.

This article reports the formation of an $\mathrm{Al}_{2} \mathrm{O}_{3}-\mathrm{SiO}_{2}$ based coating film on the surface of high chromium steel along with the evaluation of its effect on the oxidation resistance in a steam atmosphere.

\section{Experimental procedure}

High chromium steel [composition $\mathrm{Cr}(11.9 \%)$, Ni $(0.6 \%)$, Mn (0.4\%), Si (0.2\%), C (0.14\%), Mo (0.10\%), Nb (0.08\%), $\mathrm{V}(0.08 \%)$, and $\mathrm{N}(0.035 \%)]$ is used as the metal substrate. Specimens are rectangular plates with dimensions of $20 \times 40 \times 2$ $\mathrm{mm}^{3}$. Surface roughness measurements indicate that the arithmetic average roughness $R_{a}$ and maximum height $R_{z}$ are 0.10 and $2.7 \mu \mathrm{m}$, respectively.

An $\mathrm{Al}_{2} \mathrm{O}_{3}$ based coating film is formed on the surface of the high chromium steel substrate using CSD. Figure 2 shows the film formation process. The surface of the high chromium steel substrate is rinsed with acetone, immersed in an $\mathrm{Al}_{2} \mathrm{O}_{3}$ based ceramic sol, and lifted at a fixed rate of $3 \mathrm{~mm} / \mathrm{s}$. The $\mathrm{Al}_{2} \mathrm{O}_{3}$ based ceramic sol used in this work (Kawaken Fine Chemicals Co., Ltd., CSA-110AD) consists of pseudo-boehmite particles with an average grain size of $3 \mathrm{~nm}$, (3-glycidoxypropyl) trimethoxysilane $\left(\mathrm{C}_{9} \mathrm{H}_{20} \mathrm{O}_{5} \mathrm{Si}\right)$, water, and methanol. The weight ratio of pseudoboehmite (as $\mathrm{Al}_{2} \mathrm{O}_{3}$ ), (3-glycidoxypropyl) trimethoxysilane (as $\mathrm{SiO}_{2}$ ), pure water, and methanol is 6.3:1.5:59.7:28. $\mathrm{C}_{9} \mathrm{H}_{20} \mathrm{O}_{5} \mathrm{Si}$ is added to enhance the adhesive strength between the coating film and the metal substrate. ${ }^{13)}$ Coated specimens are dried at room temperature, heat treated in air for $15 \mathrm{~min}$ at $423 \mathrm{~K}$ with an electric oven, and then used in steam oxidation tests. Specimens without coating are also tested for comparison.

The thermal decomposition properties of the ceramic precursor are evaluated by drying the ceramic sol at room temperature and then conducting a thermogravimetric and differential thermal analysis (TG/DTA, SII Nanotechnology Inc., TG/DTA 320). The evaluation conditions entail an air flow rate of $200 \mathrm{ml} / \mathrm{min}$ and a heating rate of $20 \mathrm{~K} / \mathrm{min}$.

Oxidation tests in a steam atmosphere are conducted for high chromium steel substrates and high chromium steel substrates with an $\mathrm{Al}_{2} \mathrm{O}_{3}$ based coating film deposited with the process described above. The test conditions are 773,873 , or $973 \mathrm{~K}$ for $1,000 \mathrm{~h}$. Figure 3 shows a schematic of the testing apparatus. A

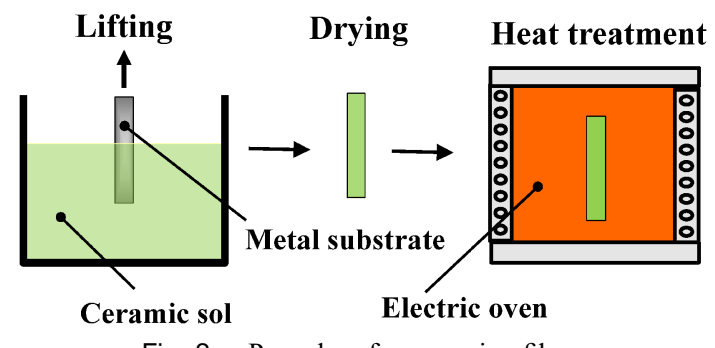

Fig. 2. Procedure for preparing films specimen is placed inside a stainless steel (JIS SUS310S) furnace tube with an inner diameter of $75 \mathrm{~mm}$. Ar gas is flowed into the furnace tube for $12 \mathrm{~h}$ at room temperature at a flow rate of 500 $\mathrm{ml} / \mathrm{min}$. The temperature is raised to $623 \mathrm{~K}$ over approximately $1 \mathrm{~h}$ while flowing Ar gas; then, steam is flowed instead of Ar gas. Regarding the steam supply, Ar gas and $\mathrm{O}_{2}$ gas are used in a deaeration tank to maintain the dissolved oxygen concentration below $7 \mathrm{ppb}$ in the pure water supplied to a steam generator at a rate of $3 \mathrm{ml} / \mathrm{min}$. All the pure water is converted into steam and flowed into the furnace tube containing the specimen. The steam generator is heated from 520 to $570 \mathrm{~K}$, and all the pure water is converted into steam while passing through the generator. The steam flowing through the furnace tube containing the specimen is naturally cooled and returned to the deaeration tank after condensation. After changing the flow gas from Ar to steam at $623 \mathrm{~K}$, the furnace temperature is raised to the designated temperature over a time span of approximately $1 \mathrm{~h}$, and then maintained at that temperature. After the test, the furnace is cooled with a cooling rate of $100 \mathrm{~K} / \mathrm{h}$ from the testing temperature to $623 \mathrm{~K}$; the flow gas is then changed from steam to Ar, and the furnace is finally cooled to room temperature.

The surface roughness of the specimens after a steam oxidation test is measured using a contact-type surface roughness tester (Kosaka Laboratory Ltd., Surfcorder SE-30C). The arithmetic average roughness $R_{a}$ and the maximum height $R_{z}$ are used to assess the surface roughness; the measurement conditions include a cutoff value of $0.8 \mathrm{~mm}$ and an evaluation length of $16 \mathrm{~mm}$, conforming to JIS B 0601. Five points are measured for each specimen, and the average value is adopted. Figure $\mathbf{4}$ shows the surface roughness measurement points. The five points are selected at $5 \mathrm{~mm}$ intervals from the center of the specimen.

The change in specimen weight during the steam oxidation test is also measured. A coated specimen is heat treated at $423 \mathrm{~K}$ for $15 \mathrm{~min}$ and $773 \mathrm{~K}$ for $1 \mathrm{~h}$ in air, and its weight reduction ratio is

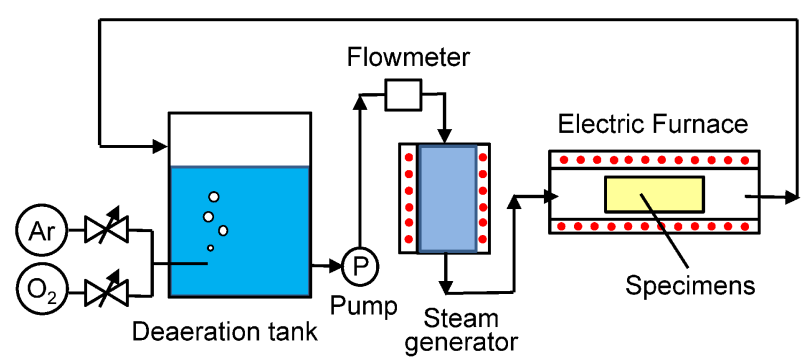

Fig. 3. Schematic illustration of testing apparatus for steam oxidation.

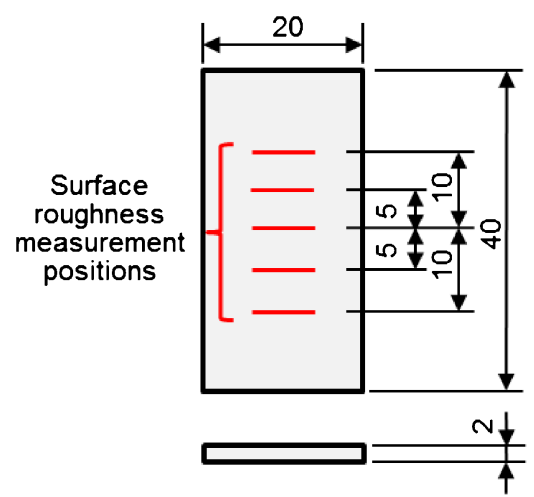

Fig. 4. Dimensions and surface roughness measurement positions of specimen. 
measured. This result is used to derive the weight reduction ratio when the $\mathrm{Al}_{2} \mathrm{O}_{3}$ coating film is completely mineralized, which is $72.8 \%$; this weight reduction ratio is considered when evaluating the change in weight during oxidation. The heat treatment condition at $773 \mathrm{~K}$ for $1 \mathrm{~h}$ is chosen as the $\mathrm{Al}_{2} \mathrm{O}_{3}$ sol used in this study completely mineralizes, and there is no further loss of weight, as discussed later.

The center is cut, embedded in resin, and the cross section is polished using diamond abrasive grains for high chromium steel specimens, with and without coating, after the steam oxidation test. Furthermore, the cross sections near the specimen surface are prepared with a cross-section polisher (CP; Jeol Ltd., IB09010CP) and observed using field emission scanning electron microscopy (FE-SEM; Jeol Ltd., JSM-7800F), while element mapping is conducted using electron probe micro analysis (EPMA; Jeol Ltd., JSM-7800F). Portions near the specimen surface are cut out in some specimens using focused ion beam (FIB; Hitachi Hi-Technologies Corp., FB-2100), observed using scanning transmission electron microscopy (STEM; Hitachi HiTechnologies Corp., HD-2000), and analyzed with energydispersive X-ray spectroscopy (EDS; Thermo Fisher Scientific K.K., Noran System Seven).

The crystal phases near the surface are identified in high chromium steel specimens, with and without coating, after a steam oxidation test using X-ray diffraction (XRD, Rigaku Corp., RINT2200). Measurements are performed with an applied voltage of $40 \mathrm{kV}$, tube current of $40 \mathrm{~mA}$, and scanning speed of $2^{\circ} / \mathrm{min}$.

\section{Results and discussion}

Figure 5 shows the TG/DTA data of the dried $\mathrm{Al}_{2} \mathrm{O}_{3}-\mathrm{SiO}_{2}$

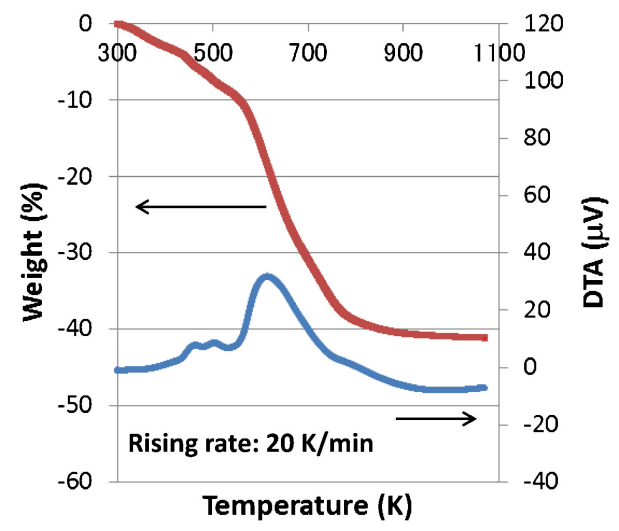

Fig. 5. TG and DTA data for alumina-based precursor.

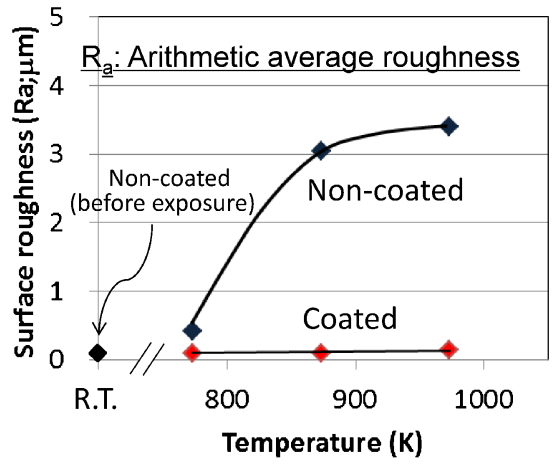

Fig. 6. Relation between temperature and surface roughness (left figure: arithmetic average roughness $R_{a}$, right figure: maximum height of surface roughness $\mathrm{R}_{\mathrm{z}}$ ) for specimens treated at different temperatures for $1,000 \mathrm{~h}$.

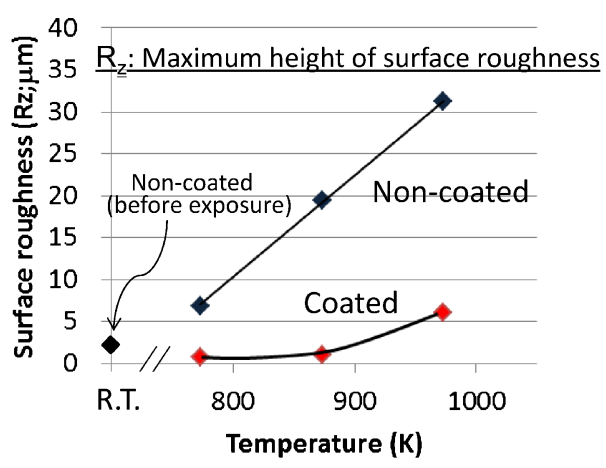

based sol. The TG measurement indicates that the loss of weight is complete at approximately $800 \mathrm{~K}$, and therefore all the organic matter has completely decomposed at that point. The heating rate is fast, $20 \mathrm{~K} / \mathrm{min}$; hence, the loss of weight is estimated to finish at a much lower temperature. A measurement of the weight change after holding each temperature for $30 \mathrm{~min}$ showed that the loss of weight is completed at $773 \mathrm{~K}$. Two small exothermic peaks between $400 \mathrm{~K}$ and $500 \mathrm{~K}$ as well as another exothermic peak near $600 \mathrm{~K}$ are observed during the weight loss.

Figure 6 shows the relation between the heat treatment temperature and the specimen surface roughness in steam oxidation tests. The heat treatment time is $1,000 \mathrm{~h}$ in all tests. The surface roughness of the high chromium steel before the steam oxidation test is also provided in the graphs for comparison. The arithmetic average roughness $R_{a}$, which is shown in the left panel of Fig. 6, is $0.1 \mu \mathrm{m}$ for the metal substrate before the steam oxidation test, but increases with increasing the temperature for specimens without coating; the values are $0.42,3.0$, and $3.4 \mu \mathrm{m}$ at 773,873 , and $973 \mathrm{~K}$, respectively. In contrast, the value for coated specimens after the steam oxidation test remains constant at $0.10 \mu \mathrm{m}$ when the temperature increases to 773 and $873 \mathrm{~K}$, but slightly increases to $0.14 \mu \mathrm{m}$ at $973 \mathrm{~K}$. The right panel of Fig. 6 shows the maximum height $R_{z}$ of the surface roughness. The value for the metal substrate before a steam oxidation test is $2.7 \mu \mathrm{m}$. After the steam oxidation test, $\mathrm{R}_{\mathrm{z}}$ significantly increases with increasing the temperature for specimens without coating, achieving the values of $6.9,19.4$, and $31.2 \mu \mathrm{m}$ at 773,873 , and $973 \mathrm{~K}$, respectively. On the other hand, in coated specimens, almost no change in $R_{z}$ is observed after the steam oxidation tests at 773 and $873 \mathrm{~K}$, as $\mathrm{R}_{\mathrm{z}}$ is equal to 0.78 and $1.0 \mu \mathrm{m}$, respectively; however, the value increases to $6.0 \mu \mathrm{m}$ at $973 \mathrm{~K}$. In summary, a significant change in surface roughness in the high chromium steel used in this study occurs between 773 and $973 \mathrm{~K}$ in a steam atmosphere. However, the increase in surface roughness can be dramatically suppressed by depositing an $\mathrm{Al}_{2} \mathrm{O}_{3}$ based coating through CSD. In particular, almost no change in surface roughness, namely, in $R_{a}$ and $R_{z}$, is found at 773 and $873 \mathrm{~K}$. The $R_{z}$ values at 773 and $873 \mathrm{~K}$ are slightly smaller than those observed in the high chromium steel substrate before testing. This may be because the slurry smoothed the unevenness of the surface of the high chromium steel substrate during dip coating.

Figure 7 shows the relation between the heating temperature in a steam atmosphere and the weight gain. The heat treatment time lasts for $1,000 \mathrm{~h}$ in all cases. For specimens without coating, there is almost no weight gain at $773 \mathrm{~K}$, but a weight gain of approximately 20 and $160 \mathrm{~g} / \mathrm{m}^{2}$ is observed at 873 and $973 \mathrm{~K}$, respectively. In contrast, for specimens with coating, there is no 
weight gain at both 773 and $873 \mathrm{~K}$, and a slight weight gain of approximately $6 \mathrm{~g} / \mathrm{m}^{2}$ is found at $973 \mathrm{~K}$. These results are very consistent with the surface roughness measurements discussed previously; therefore, the $\mathrm{Al}_{2} \mathrm{O}_{3}$ based coating is found to significantly suppress the weight gain due to oxidation.

Figure 8 shows the FE-SEM observation results of a cross section near the surface of the high chromium steel substrate without coating heat treated at $873 \mathrm{~K}$ for $1,000 \mathrm{~h}$ in a steam atmosphere. The surface of the substrate exhibits an oxide film consisting of two layers: an outer layer (portion A) and an inner layer (portion B). The outer layer has a thickness of approximately $10-20 \mu \mathrm{m}$, is very uneven, and partially contains relatively large pores. The inner layer is non-uniform and contains

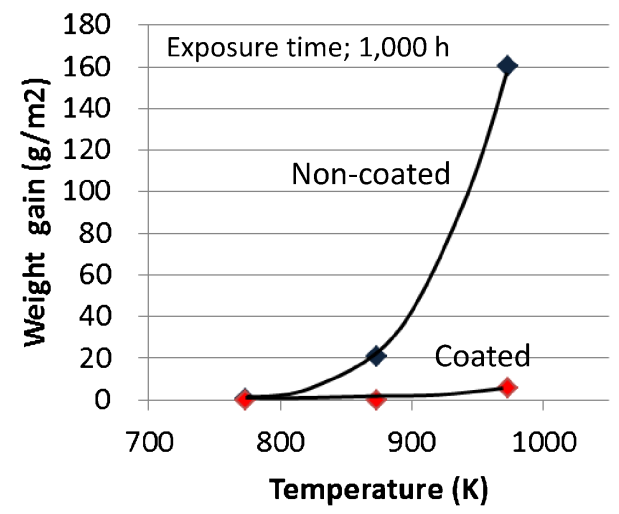

Fig. 7. Relation between temperature and weight gain after steam oxidation test for specimens treated at different temperatures for $1,000 \mathrm{~h}$. many fine pores. The inner layer does not exist in some regions, where only the outer layer can be observed. Remarkably, the thickness of the outer layer is small in the regions without the inner layer, and large in the regions with the inner layer. This increases the unevenness of the outer layer, and may lead to the increase in surface roughness, as shown in Fig. 6. The positioning of the layers against the substrate suggests that the outer layer grows outward from the substrate, whereas the inner layer grows inward from the substrate surface.

Figure 9 shows the EPMA analysis for the same view of a specimen without coating. Strong signals from $\mathrm{Fe}$ and $\mathrm{O}$ are found in the outer layer (portion A) formed on the surface of the high chromium steel substrate; therefore, this layer is expected to consist of iron oxides. On the other hand, the inner layer (portion B) consists of regions with high concentration of $\mathrm{Fe}, \mathrm{Cr}$, and $\mathrm{O}$, and regions consisting of only $\mathrm{Cr}$ and $\mathrm{O}$. The latter regions, which include $\mathrm{Cr}-\mathrm{O}$ compounds, surround the former regions, which include $\mathrm{Fe}-\mathrm{Cr}-\mathrm{O}$ compounds. The high chromium steel substrate consists of $\mathrm{Fe}$ and $\mathrm{Cr}$, and a layer where $\mathrm{Cr}$ concentrates is also found near the substrate surface.

Figure 10 shows the XRD results of a high chromium steel specimen without coating heat treated at $873 \mathrm{~K}$ for $1,000 \mathrm{~h}$. The obtained diffraction peaks completely match those of $\mathrm{Fe}_{3} \mathrm{O}_{4}$ (hematite) and $(\mathrm{Fe}, \mathrm{Cr})_{3} \mathrm{O}_{4}$ with the same crystal structure. Furthermore, minute peaks of $\alpha$-Fe (ferrite) originating from the substrate are also found. The measurements in Figs. 8-10 suggest that the outer layer formed on the substrate surface consists of $\mathrm{Fe}_{3} \mathrm{O}_{4}$, whereas the inner layer comprises $(\mathrm{Fe}, \mathrm{Cr})_{3} \mathrm{O}_{4}$ and $\mathrm{Cr}-\mathrm{O}$ compounds.

Ueda et al. claimed that a two-layer structure forms during the
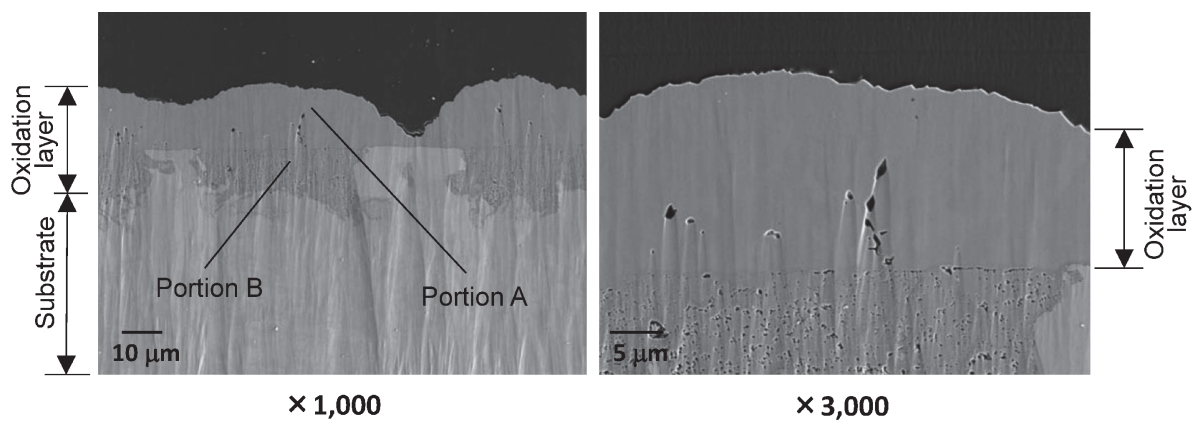

Fig. 8. Secondary-electron image of cross section for non-coated metal specimen after steam oxidation test heat-treated at $873 \mathrm{~K}$ for $1,000 \mathrm{~h}$

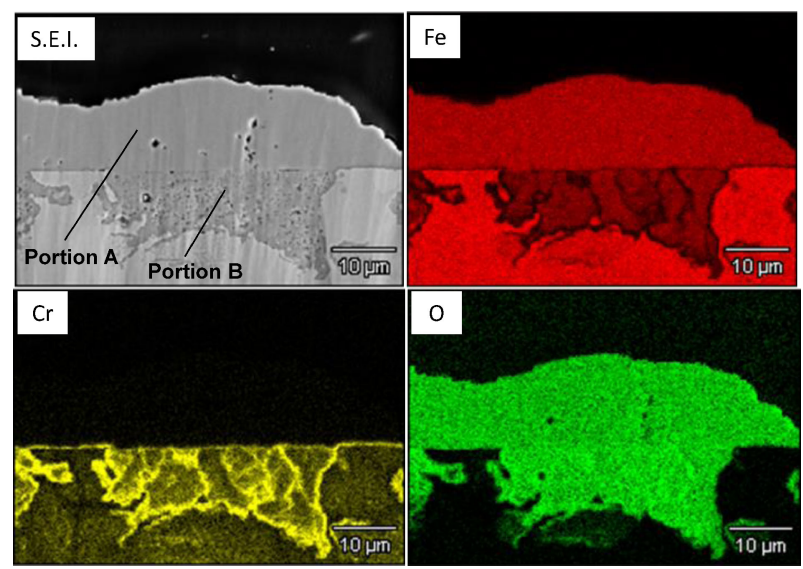

Fig. 9. EPMA analysis of cross section for non-coated metal specimen after steam oxidation test heat-treated at $873 \mathrm{~K}$ for $1,000 \mathrm{~h}$.

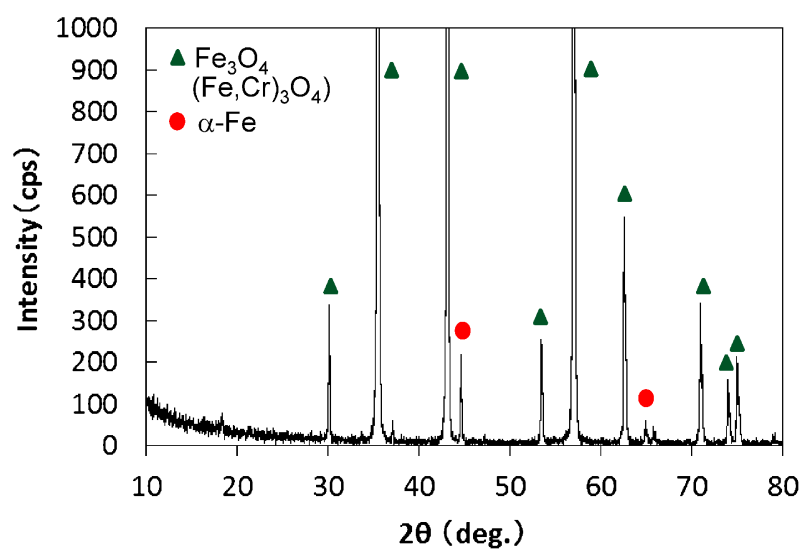

Fig. 10. Results of X-ray diffraction analysis for non-coated specimen after steam oxidation test heat treated at $873 \mathrm{~K}$ for $1,000 \mathrm{~h}$. 


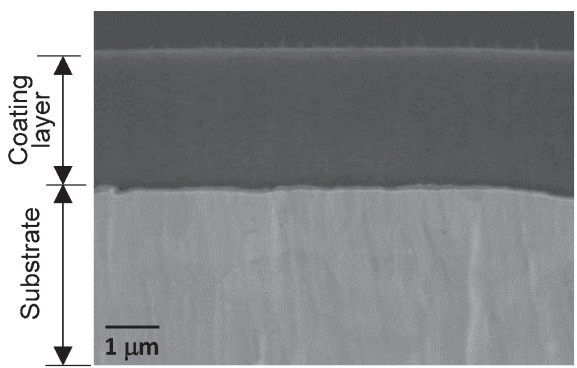

(a) $873 \mathrm{~K}$ for $1,000 \mathrm{~h}$

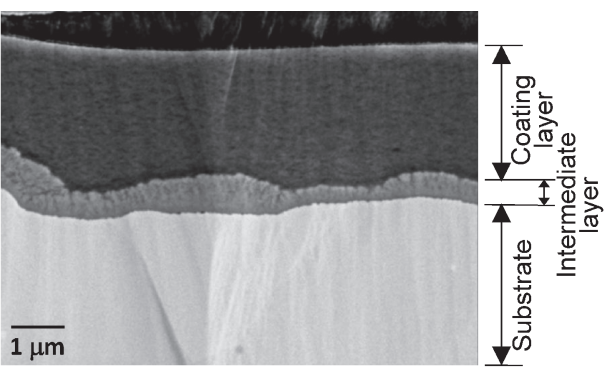

(b) $973 \mathrm{~K}$ for $1,000 \mathrm{~h}$

Fig. 11. Secondary-electron image of cross section for coated metal specimens after steam oxidation test heat-treated at $873 \mathrm{~K}$ and $973 \mathrm{~K}$ for $1,000 \mathrm{~h}$.

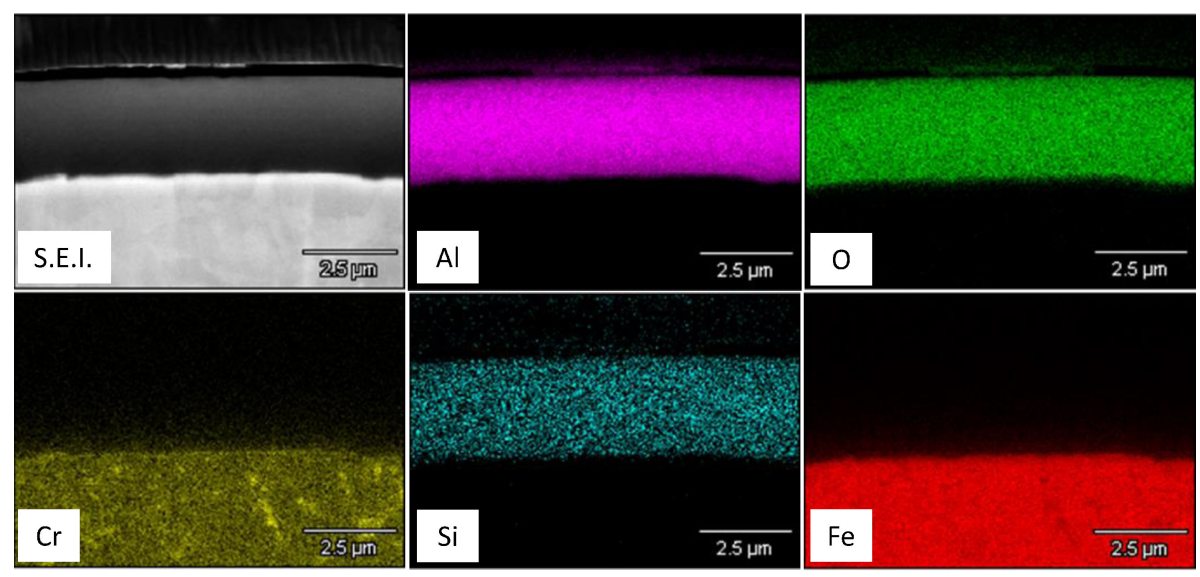

Fig. 12. EPMA analysis of cross section of coated metal specimen after steam oxidation test heat-treated at $873 \mathrm{~K}$ for $1,000 \mathrm{~h}$.

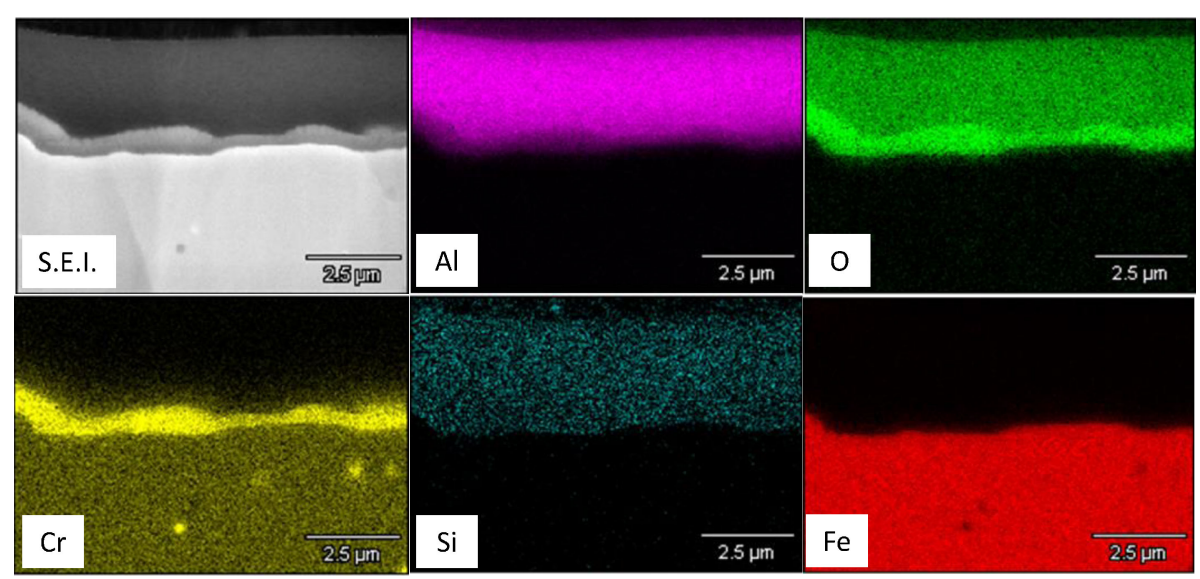

Fig. 13. EPMA analysis of cross section for coated metal specimen after steam oxidation test heat-treated at $973 \mathrm{~K}$ for $1,000 \mathrm{~h}$.

steam oxidation of ferrite steels; the outer layer is $\mathrm{Fe}_{3} \mathrm{O}_{4}$ and the inner layer is $(\mathrm{Fe}, \mathrm{Cr})_{3} \mathrm{O}_{4}$. The rate limiting step in the growth of the outer layer is the outward diffusion of the Fe ions, whereas that of the inner layer is the inward diffusion of the $\mathrm{O}$ ions. ${ }^{14)}$ Fujikawa et al. found that local layers with high $\mathrm{Cr}$ concentration form in the inner layer of high chromium ferrite steel, and the formation of a high $\mathrm{Cr}$ content layer at the oxide film/alloy interface is especially pronounced in $12 \mathrm{Cr}$ steel. ${ }^{15}$ ) The results of our experiments agree well with these reports; however, the formation of the inner layer was non-uniform, and, in some regions, only the outer layer was found. The reason is currently not clear, although it is possible that the high $\mathrm{Cr}$ concentration layer formed on the surface of the high chromium steel substrate at an early stage, owing to unknown reasons, inhibited the $\mathrm{Fe}$ diffusion. The reason why the thickness of the outer layer is small in regions with no inner layer and conversely large in regions with an inner layer can be attributed to the diffusion process. As the outward diffusion of $\mathrm{Fe}$ is significant in regions with a thick outer layer, $\mathrm{Cr}$ can easily move into the depleted layer formed by the Fe diffusion to form the morphology that is observed.

Figure 11 shows the FE-SEM observation results for regions near the surface of the coated high chromium steel specimens that 
have been heat treated at 873 or $973 \mathrm{~K}$ for $1,000 \mathrm{~h}$ in a steam atmosphere. A $2-3 \mu \mathrm{m}$ thick film, which is presumed to be the coating layer, can be observed in both specimens. A very thin intermediate layer with a thickness below $0.1 \mu \mathrm{m}$, and located between the film presumed to be the coating layer and the metal substrate, is visible in the specimen heat treated at $873 \mathrm{~K}$ for $1,000 \mathrm{~h}$. In contrast, a clear intermediate layer approximately $0.5 \mu \mathrm{m}$ thick can be found between the film presumed to be the coating layer and the metal substrate in the specimen heat treated at $973 \mathrm{~K}$ for $1,000 \mathrm{~h}$. In both cases, there are no gaps or peeling at the interface, and the coating film is firmly attached to the metal substrate.

Figure 12 shows the EPMA analysis results of a specimen heat treated at $873 \mathrm{~K}$ for $1,000 \mathrm{~h}$; the view is the same as that in Fig. 11(a). The distribution of $\mathrm{Al}, \mathrm{Si}$, and $\mathrm{O}$ is close to uniform in the film presumed to be the coating layer. $\mathrm{Fe}$ and $\mathrm{Cr}$ distribute within the metal substrate. There are some regions where $\mathrm{Cr}$ is highly concentrated, but there is no significant segregation near the ceramic coating layer/metal substrate interface. Figure 13 shows the EPMA results of a specimen heat treated at $973 \mathrm{~K}$ for $1,000 \mathrm{~h}$. The view is the same as that in Fig. 11(b). Again, Fe and $\mathrm{Cr}$ distribute in the metal substrate and there are some regions with high $\mathrm{Cr}$ content. $\mathrm{Al}, \mathrm{Si}$, and $\mathrm{O}$ distribute in the film presumed to be the coating layer, while a high concentration of $\mathrm{Cr}$ is found near the metal substrate/ceramic coating layer interface. There is no $\mathrm{Fe}$ in the region where $\mathrm{Cr}$ is highly concentrated; instead, $\mathrm{Al}, \mathrm{Si}$, and $\mathrm{O}$, which constitute the coating layer, are found. It was suggested that the diffusion occurred at the interface between high chromium steel substrate and $\mathrm{Al}_{2} \mathrm{O}_{3}-$ $\mathrm{SiO}_{2}$ based coating film. In any case, the presence of iron oxides, which are found in specimens without coating, cannot be observed.

STEM observation and EDS analysis were also conducted on the intermediate layer. Figure 14 shows a STEM image near the surface of the coated high chromium steel substrate heat treated at $973 \mathrm{~K}$ for $1,000 \mathrm{~h}$ in a steam atmosphere. An intermediate layer approximately $0.5 \mu \mathrm{m}$ thick is found, as in the FE-SEM observation. The intermediate layer/high chromium steel substrate interface and the intermediate layer/coating layer interface both have good integrity and there are no gaps or cracks. Figure 15 shows the EDS analysis results near the intermediate layer of the same specimen. The results show that this intermediate layer comprises $\mathrm{Cr}, \mathrm{Mn}, \mathrm{Al}, \mathrm{Si}$, and $\mathrm{O}$. There is no significant segregation, and the stoichiometry is relatively uniform within the intermediate layer. The diffusion of $\mathrm{Mn}$ is observed in the $\mathrm{Al}_{2} \mathrm{O}_{3}-\mathrm{SiO}_{2}$ coating side.
Figure 16 shows the XRD results of the surfaces of coated high chromium steel specimens heat treated at 873 and $973 \mathrm{~K}$, respectively, for $1,000 \mathrm{~h}$ in a steam atmosphere. No significant diffraction peaks, other than peaks from $\alpha$-Fe in the substrate, are observed in the specimen heat treated at $873 \mathrm{~K}$ for $1,000 \mathrm{~h}$. In contrast, weak, relatively broad peaks are found in addition to the $\alpha$-Fe peaks from the substrate in the specimen heat treated at $973 \mathrm{~K}$ for $1,000 \mathrm{~h}$. These peaks accord considerably well at those observed for $\theta-\mathrm{Al}_{2} \mathrm{O}_{3}$; however, as the match is not perfect, the pattern cannot be definitely identified as $\theta-\mathrm{Al}_{2} \mathrm{O}_{3}$. There is a possibility that the film is oriented. If this assumption is correct, these peaks are likely to originate from a phase transition in the ceramic coating layer with the temperature increase instead of the intermediate layer observed in FE-SEM. However, the origin is inconclusive at this point.

The ceramic coating layer is thought to suppress the surface roughness change because the steam does not come in direct contact with the high chromium steel substrate. However, pores with sizes ranging from a few to a few tens of nanometers are known to typically form in films grown by CSD. ${ }^{16)-18)}$ This is because the organic content in the ceramic precursor exits through the ceramic coating during the thermal decomposition, and the paths through which the organic content moved remain as pores. A gradual steam oxidation at high temperature in coated specimens is considered to occur as a result of the steam gradually passing through these pores, and reaching and oxidizing the high chromium steel surface. Choi et al. dip coated a $\mathrm{TiO}_{2}$ alkoxide solution on borosilicate glass and measured the pore distribution in the coating film after heat treatment at $773 \mathrm{~K}$ for $15 \mathrm{~min}$. They reported that the pore size is distributed between 3

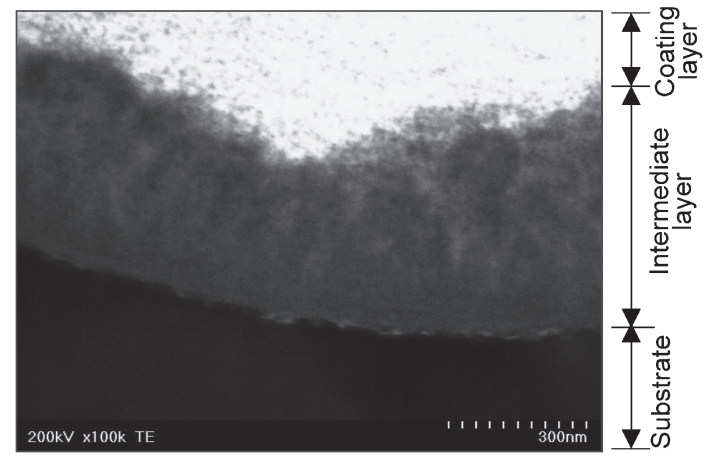

Fig. 14. STEM image of cross section for coated metal specimen after steam oxidation test heat-treated at $973 \mathrm{~K}$ for $1,000 \mathrm{~h}$.

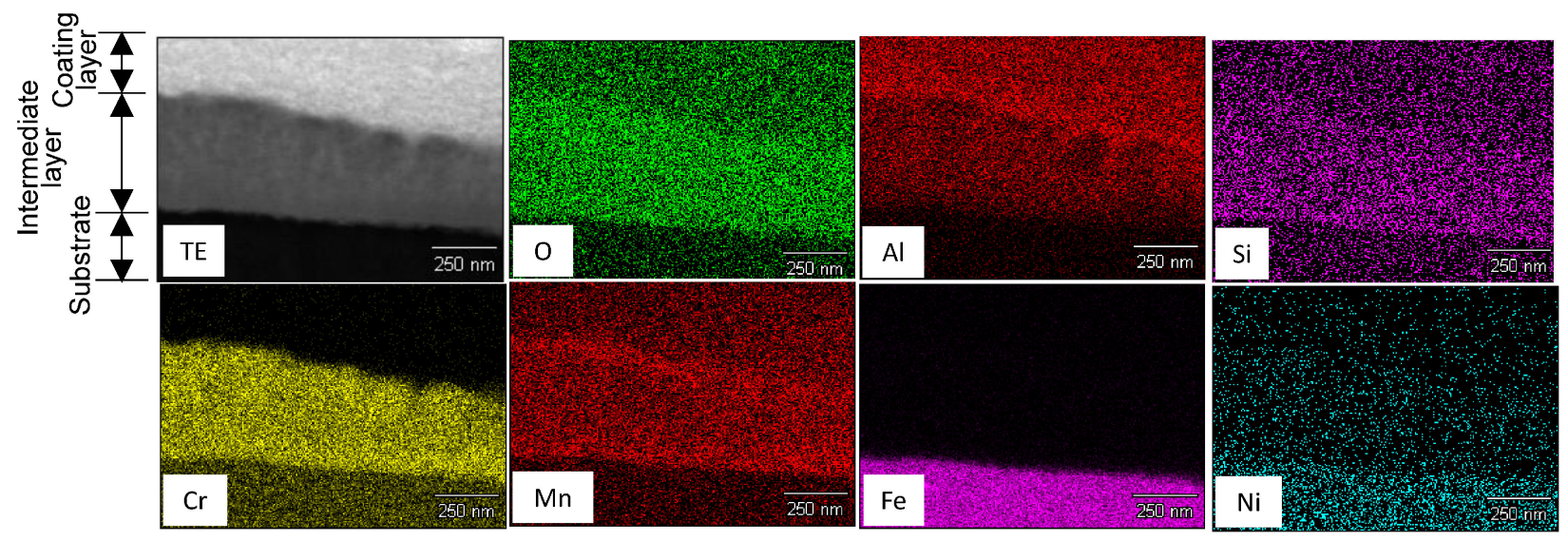

Fig. 15. EDS analysis of cross section for coated metal specimen after steam oxidation test heat-treated at $973 \mathrm{~K}$ for $1,000 \mathrm{~h}$. 

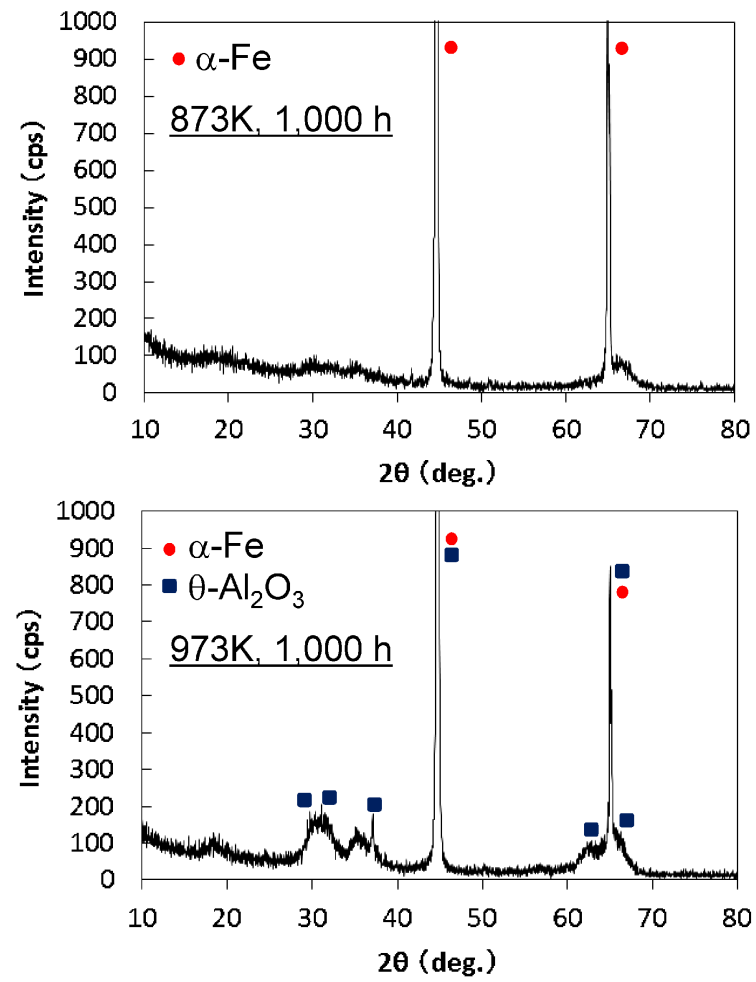

Fig. 16. Results of X-ray diffraction analysis for coated specimens after steam oxidation test heat treated at $873 \mathrm{~K}$ and $973 \mathrm{~K}$ for $1,000 \mathrm{~h}$.

and $8 \mathrm{~nm} .{ }^{16)}$ Guo et al. prepared a sol of $\mathrm{Nb}_{2} \mathrm{O}_{5}$ by hydrolysis of an ethanol solution of $\mathrm{NbCl}_{5}$. They coated glass substrates with the sol, measured the pore distribution after heat treatment at temperatures ranging from 673 to $923 \mathrm{~K}$ in air, and found that the average pore size ranged from 8.5 to $23.7 \mathrm{~nm}$, with a tendency to increase with increasing the heat treatment temperature. ${ }^{17)}$ The pore size is highly affected by the type of precursor and the film formation process, as discussed above; reducing the pore size is crucial to obtain films with higher oxidation resistance.

\section{Conclusions}

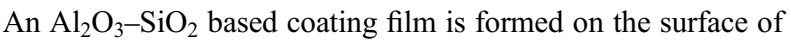
a high chromium steel substrate using CSD to suppress the increase in surface roughness due to steam oxidation. After an oxidation test at $873 \mathrm{~K}$ for $1,000 \mathrm{~h}$ in a steam atmosphere, the arithmetic average roughness $R_{a}$ and maximum height $R_{z}$ for high chromium steel without coating were 3.0 and $19.4 \mu \mathrm{m}$, respectively. In contrast, the values for high chromium steel with an $\mathrm{Al}_{2} \mathrm{O}_{3}-\mathrm{SiO}_{2}$ based coating after testing under the same conditions were 0.10 and $1.0 \mu \mathrm{m}$, respectively, demonstrating that the forma- tion of a coating film significantly suppresses the increase in surface roughness.

The observation of the regions near the surface shows that a very uneven oxide film consisting of $\mathrm{Fe}_{3} \mathrm{O}_{4}$ forms in high chromium steel without coating; the formation of this oxide layer is considered to increase the surface roughness. On the other hand, in high chromium steel with an $\mathrm{Al}_{2} \mathrm{O}_{3}-\mathrm{SiO}_{2}$ based coating film, the oxide film consisting of $\mathrm{Fe}_{3} \mathrm{O}_{4}$ does not form, and only the $\mathrm{Al}_{2} \mathrm{O}_{3}-\mathrm{SiO}_{2}$ based film can be observed on the surface. Moreover, an intermediate layer consisting of $\mathrm{Cr}, \mathrm{Mn}, \mathrm{Al}, \mathrm{Si}$, and $\mathrm{O}$ is confirmed to form at the interface between the high chromium steel substrate and the $\mathrm{Al}_{2} \mathrm{O}_{3}-\mathrm{SiO}_{2}$ based coating film when the heat treatment temperature is increased to $973 \mathrm{~K}$ for $1,000 \mathrm{~h}$.

\section{References}

1) D. Mudgal, S. Singh and S. Prakash, J. Minerals \& Materials Characterization \& Engineering, 11, 211-213 (2012).

2) T. Sundararajan, S. Kuroda, T. Itagaki and F. Abe, ISIJ Int., 43, 104-111 (2003).

3) K. Minegishi, Y. Koiwai, Y. Kikuchi, K. Yano, M. Kasuga and A. Shimizu, Jpn. J. Appl. Phys., 36, L1453-L1455 (1997).

4) Y. Yang, J. L. Ong and J. Tian, Biomaterials, 24, 619-627 (2003).

5) S. Ono and Y. Nishi, J. Am. Ceram. Soc., 84, 3054-3056 (2001).

6) T. Hagiwara, N. Ogata, N. Nagata and Y. Sakamoto, Cem. Sci. Concr. Technol., 54, 141-145 (2000).

7) C. J. Brinker, G. C. Frye, A. J. Hurd and C. S. Ashley, Thin Solid Films, 201, 97-108 (1991).

8) H. Uchihashi, N. Tohge and T. Minami, J. Ceram. Soc. Japan, 97, 396-399 (1989).

9) S. K. Tiwari, T. Mishra, M. K. Gunjan, A. S. Bhattacharyya, T. B. Singh and R. Singh, Surf. Coat. Tech., 201, 7582-7588 (2007).

10) O. D. Santics, L. Gomez, N. Pellegri, C. Parodi, A. Marajofsky and A. Duran, J. Non-Cryst. Solids, 121, 338-343 (1990).

11) M. Atik, J. Zarzycki and C. R'kha, J. Mater. Sci. Lett., 13, 266269 (1994)

12) M. Guglielmi, D. Festa, P. C. Innocenzi, P. Colombo and M. Gobbin, J. Non-Cryst. Solids, 147-148, 474-477 (1992).

13) W. Brostow and T. Datashvili, Chem. \& Chemical Tech., 2, 2732 (2008).

14) M. Ueda and T. Maruyama, Zairyo-to-Kankyo, 54, 175-182 (2005).

15) H. Fujikawa and N. Otsuka, Nippon Kagaku Kaishi, 1, 45-59 (1998).

16) H. Choi, E. Stathatos and D. D. Dionysiou, Appl. Catal., B. Environmental, 63, 60-67 (2006).

17) P. Guo and M. A. Aegerter, Thin Solid Films, 351, 290-294 (1999).

18) M. F. M. Zwinkels, S. G. Jaras and P. G. Menon, J. Mater. Sci., 31, 6345-6349 (1996). 